\title{
Attitudes to statistics in primary health care physicians, Qassim province
}

\author{
Saulat Jahan ${ }^{1}$, Abdullah Mohammed Al-Saigul ${ }^{2}$ and Amel Abdalrhim Suliman ${ }^{3}$ \\ ${ }^{1}$ Public Health Specialist, Research and Information Unit, Public Health Administration, Qassim, Saudi Arabia \\ ${ }^{2}$ Chief, Research and Information Unit, Public Health Administration, Qassim, Saudi Arabia \\ ${ }^{3}$ Public Health Specialist, Research and Information Unit, Public Health Administration, Qassim, Saudi Arabia
}

\begin{abstract}
Aim: To investigate primary health care (PHC) physicians' attitudes to statistics, their self-reported knowledge level, and their perceived training needs in statistics. Background: In spite of realization of the importance of statistics, inadequacies in physicians' knowledge and skills have been found, underscoring the need for in-service training. Understanding physicians' attitudes to statistics is vital in planning statistics training. Methods: The study was based on theory of planned behavior. A crosssectional survey of all PHC physicians was conducted in Qassim province, from August to October 2014. Attitudes to statistics were determined by a self-administered questionnaire. The attitudes were assessed on four subscales including general perceptions; perceptions of knowledge and training; perceptions of statistics and evidence-based medicine; and perceptions of future learning. Findings: Of 416 eligible participants, 338 $(81.25 \%)$ responded to the survey. On a scale of $1-10$, the majority $(73.6 \%)$ of the participants self-assessed their level of statistics knowledge as five or below. The attitude scores could have a minimum of 20 and a maximum of 100, with higher scores showing a positive attitude. The participants showed a positive attitude with the mean score of $71.14( \pm 7.73)$. Out of the four subscales, 'perceptions of statistics and evidence-based medicine' subscale scored the highest, followed by 'perceptions of future learning'. Conclusion: PHC physicians have a positive attitude to statistics. However, they realize their gaps in knowledge in statistics, and are keen to fill these gaps. Statistics training, resulting in improved statistics knowledge is expected to lead to clinical care utilizing evidence-based medicine, and thus improvement to health care services.
\end{abstract}

Key words: attitude; primary health care; Qassim; Saudi Arabia; statistics

Received 9 July 2015; revised 10 October 2015; accepted 26 October 2015;

first published online 23 November 2015

\section{Introduction}

The knowledge of statistics is essential for interpreting research in health sciences and understanding evidence-based medicine. With growing literature on evidence-based medicine and its increasing utilization in clinical practice, learning statistics has become vital for practicing physicians (Windish et al., 2007; Sami, 2010).

Correspondence to: Dr Saulat Jahan, c/o Dr Syed Amjad Ali Omar, Consultant (A), Ophthalmology Department, King Fahd Specialist Hospital, PO Box 2290, Buraidah, Qassim, Saudi Arabia. Email: saulatjahan@hotmail.com

(C) Cambridge University Press 2015
Although physicians increasingly realize the importance of statistics, various studies have shown physicians' inadequacies in the knowledge of statistics and in the skills of applying statistical tests (West and Ficalora, 2007; Kilic and Celik, 2013). Research has also shown that practicing physicians did not have a proper understanding of statistical tests commonly used in published research, and had difficulty in interpreting study results (Windish et al., 2007).

Primary health care (PHC) is the cornerstone of the health care system. Quality health services at primary care are vital for a healthy community. For quality health care, the primary care 
physicians must keep abreast of current clinical information to practice evidence-based medicine. To understand evidence-based medicine literature, primary care physicians require to comprehend the research studies and should be able to interpret their results. It has been reported that the physicians perceive statistics as a difficult subject, and this perception affects their attitudes to statistics (Kilic and Celik, 2013).

Studies have shown that attitudes play a significant role in learning statistics (Zhang et al., 2012). Thus, it is important to determine the attitudes of the target participants, before planning educational programs related to statistics. Various studies have been conducted to determine the attitudes of students to statistics in different fields including psychology and nursing (Zimprich, 2012; Baghi and Kornides, 2013; Mathew and Aktan, 2014). Some studies were also conducted to assess physicians' attitudes to statistics (Ercan et al., 2008; Rashid and Subramaniam, 2012; Zhang et al., 2012; Kilic and Celik, 2013). However, there is a dearth of literature regarding attitudes to statistics among physicians in general and PHC physicians in particular. On literature search, no such study could be found from Saudi Arabia. The Ministry of Health $(\mathrm{MOH})$ is the main provider of $\mathrm{PHC}$ in Saudi Arabia. Most PHC doctors are general physicians with a degree of bachelors in medicine. These physicians are professional leaders at PHC centers. The $\mathrm{MOH}$ has a variety of PHC programs including Antenatal Care and Childhood Immunization. Data for these programs are collected at the level of PHC centers. Physicians are expected to comprehend those data, and support the allied staff in data management at the PHC centers. Thus, strengthening physicians' skills in statistics is required to carry out the activities such as assessment of program performance, quality assurance, and performance improvement projects. In Saudi Arabia, there is a culturally diverse health care workforce with varied educational and professional experiences with regards to statistics. In this situation, it is even more important to determine the physicians' attitudes to statistics. Understanding physicians' attitudes to statistics will be helpful in planning in-service training related to statistics.

To understand the attitudes to statistics, held by PHC physicians, we surveyed all PHC physicians in Qassim province to measure these attitudes and explore related factors. The purpose of the study was to investigate $\mathrm{PHC}$ physicians' attitudes to statistics; to determine PHC physicians' selfreported knowledge level in statistics; and to determine PHC physicians' perceived training needs in statistics. The results of this study will be helpful in designing a training course on statistics for PHC physicians.

\section{Theoretical framework}

The study was based on theory of planned behavior (Ajzen, 1991). According to this theory, human behavior is logical and there is a reason for people behaving the way that they do (DeBarr, 2004). The basic concept of the theory is that behavior change occurs if the person has an intention to change, and two main factors influence the intentions; attitudes toward the behavior and subjective norm toward the behavior (DeBarr, 2004).

As human behavior is logical, one should be able to explain or predict it. Behavioral intentions are the best predictors of human behavior, and the best predictors of a person's stated behavioral intentions are the attitude and subjective norm. Attitudes are the positive or negative feelings toward a concept, behavior, or an individual. The attitude toward a particular behavior can be predicted by examining what is the expectation regarding the outcome of a particular action and the likelihood of achieving this outcome (DeBarr, 2004). Subjective norms are a positive or negative judgment of the friends or colleagues about a particular behavior. Subjective norms are affected by normative beliefs, which means that a person is concerned about the approval of adopted behavior by the significant others, and is motivated to comply with their potential approval (Schiavo, 2007). This theory emphasizes that actual behavioral control is dependent upon resources and opportunity (DeBarr, 2004). Perceived control over the resources and opportunities required to perform a behavior, is believed to be an important aspect of behavior change processes. Theory of planned behavior has been applied to various areas such as education and health care.

\section{Methods}

The study was a cross-sectional survey. The survey included physicians working in PHC centers in Qassim province. A semi-structured, 
self-administered questionnaire was used as the survey instrument. The primary purpose of the questionnaire was to determine the physicians' attitudes to statistics.

The concepts of theory of planned behavior were applied in designing this survey. According to the theory of planned behavior, the intentions can be assessed by attitudes toward the desired behavior and subjective norms toward the behavior (DeBarr, 2004). The statements of the questionnaire were developed to determine these components of theory of planned behavior. Thus, the survey also helped in determining the intention of the participants to adopt the behavior of using statistics in their routine daily work.

The questionnaire comprised questions for gathering information about (a) baseline profile of the participants concerning their demographic information as well as data about statistics courses attendance; (b) attitudes to statistics; (c) participants' opinion concerning perceived need of training in statistics. The attitude instrument was developed through literature consultation, and the statements were adapted from validated existing surveys that addressed attitudes to statistics (West and Ficalora, 2007; Windish et al., 2007; Zhang et al., 2012; Zimprich, 2012). In our study, the attitude was determined by a 20 -item survey. The 20-item survey consisted of four subscales: (i) general perceptions: assessed participants' positive and negative feelings about statistics (eg, 'I find statistics to be very logical and clear'); (ii) perceptions of knowledge and training: described participants' perceptions about how well they are trained in statistics (eg, 'My training in statistics is adequate for my needs'); (iii) perceptions of statistics and evidence-based medicine: captured attitudes about the usefulness and importance of statistics and evidence-based medicine (eg, 'Statistics is an important part of evidence-based medicine'); and (iv) perceptions of future learning: measured participants' opinions about learning statistics in future (eg, 'I would like to study statistics'). Each subscale contained five statements pertaining to the topic of the subscale. The items were measured on a five-point Likert scale, with ' 1 ' indicating that the participants disagreed strongly with the statement and ' 5 ' suggesting that they agreed strongly with the statement. Seven of the 20 items were negatively worded; the remaining 13 items were positively worded. During analysis, negatively worded items were reversed so that higher scores always indicated a more positive attitude.

The questionnaire was piloted with the physicians working in health care facilities in Qassim. The physicians were asked to provide comments about the questionnaire, including length of the questionnaire, clarity of questions, and response options. The necessary changes were made according to their comments.

In Saudi Arabia, well-established PHC system exists. The MOH operates 2259 PHC centers in Saudi Arabia. Each center provides preventive, curative, and health education activities (Ministry of Health, 2013). The managerial structure of PHC in health directorates of Saudi provinces comprises mid-level managers in each health sector or supervisory office. A health sector or supervisory office is an administrative unit that supervises and manages health services in a specified number of PHC centers. Qassim is the northern central province of Saudi Arabia with a population of $>1.3$ million, during the year 2013. Saudi nationals comprise 1.01 million, whereas non-Saudis comprise 0.33 million of the population (Ministry of Health, 2013). In 2013, there were 159 PHC centers in Qassim (Ministry of Health, 2013). These centers primarily serve the Saudi nationals and also provide health care facilities to a limited number of non-Saudis.

All PHC physicians in Qassim province were invited to participate. A total of 416 eligible study participants were invited by an official letter issued by the highest authority for Public Health Administration, Qassim. The survey was conducted from August 14 to October 30, 2014. The survey instrument was distributed through an official mailing system. A package in an envelope containing a cover letter, informed consent forms, and the questionnaires, was posted for physicians working in the respective health sector, through the official mail to all supervisory offices in Qassim province. A return date of two weeks after receipt of the questionnaire was requested. Non-responders were followed up by telephone reminders. The district supervisors returned the completed questionnaires via official mail.

Data were analyzed using the software IBM Statistical Package for Social Sciences for Windows version 21 (Chicago, IL, 2012). The negative statements were changed to positive, with a score 
of one being counted as five and a score of five as one. Missing data on single statements were replaced by mean value substitution when processing the subscale (Green and Salkind, 2011). The mean value substitution was only done if out of the total five, two or less values were missing. Descriptive statistics were computed such as mean and standard deviation, frequency and proportions. Likert-type items were compared using Pearson's correlation coefficient, paired $t$-test, and one-way analysis of variance (ANOVA) $F$-test. A $P$-value of 0.05 or less was considered as statistically significant. Cronbach's $\alpha$ reliability coefficient of the instrument was assessed.

Content analysis of the open-ended question about suggestions for topics of the statistics training was conducted. The responses were grouped into categories emergent from the data. These categories comprised single words or phrases that described and summarized the responses given. Any participant's response could appear under more than one category if mentioning several topics relevant to different categories; thus, there were more comments than participants responding to the question. Differences in ideas about coding, including naming and constitution of categories, and classification of responses were discussed and finalized after developing consensus among the authors.

Ethical approval was obtained from Regional Research Ethics Committee. An informed consent was taken from the participants. The questionnaires were kept anonymous. Each questionnaire was given a unique identifier that was used in the management of data.

\section{Results}

Of 416 eligible participants, 338 PHC physicians working in Public Health Administration, Qassim, participated in the study. Thus, the survey response rate was $81.25 \%(338 / 416)$. The mean age of the participants was $40.8( \pm 9.3)$ years, whereas the mean duration since graduation was $14.8( \pm 8.9)$ with a minimum of less than one year and a maximum of 38 years. The demographic data of the participants are shown in Table 1. The participants included 204 $(60.9 \%)$ males and 131 (39.1\%) females. The frequencies of nationalities showed that $43.0 \%$ of the participants were Sudanese, followed by Egyptians (33.6\%) and Pakistanis (7.9\%). A majority (84.8\%) of the participants were graduates having only a bachelors degree in medicine.

The participants were asked questions to determine their interest and training in statistics (Table 2). Over half the participants (59.6\%) reported being trained in statistics during academic training and $15.2 \%$ attended statistics

Table 1 Demographic characteristics of the participants $(n=338)$

\begin{tabular}{lrr}
\hline Variables & Number & Percent \\
\hline Gender $(n=335)$ & & \\
Male & 204 & 60.9 \\
Female & 131 & 39.1 \\
Nationality $(n=330)$ & 142 & \\
Sudanese & 111 & 43.0 \\
Egyptian & 26 & 33.6 \\
Pakistani & 17 & 7.9 \\
Saudi & 11 & 5.2 \\
Indian & 23 & 3.3 \\
Others & & 7.0 \\
Qualification $(n=276)$ & 234 & 84.8 \\
MBBS & 26 & 9.4 \\
Diploma & 11 & 4.0 \\
Master & 5 & 1.8 \\
Others & & \\
\hline
\end{tabular}

Table 2 Participants' training and interest in statistics

\begin{tabular}{|c|c|c|}
\hline Variables & Number & Percent \\
\hline \multicolumn{3}{|c|}{$\begin{array}{l}\text { Studied statistics during academic } \\
\text { training }(n=337)\end{array}$} \\
\hline Yes & 201 & 59.6 \\
\hline No & 136 & 40.4 \\
\hline \multicolumn{3}{|c|}{$\begin{array}{l}\text { Attended statistics course/s after } \\
\text { graduation }(n=335)\end{array}$} \\
\hline Yes & 51 & 15.2 \\
\hline No & 284 & 84.8 \\
\hline \multicolumn{3}{|c|}{$\begin{array}{l}\text { Number of statistics courses attended } \\
\text { during last } 5 \text { years }(n=336)\end{array}$} \\
\hline No statistics course & 322 & 95.8 \\
\hline One statistics course & 11 & 3.3 \\
\hline Two statistics courses & 3 & 0.9 \\
\hline \multicolumn{3}{|c|}{$\begin{array}{l}\text { Read/looked at any report about health } \\
\text { statistics in Saudi Arabia during the } \\
\text { past } 6 \text { months }(n=337)\end{array}$} \\
\hline No & 252 & 74.8 \\
\hline Yes & 85 & 25.2 \\
\hline \multicolumn{3}{|c|}{$\begin{array}{l}\text { Read/looked at any report about health } \\
\text { statistics in Qassim during the past } \\
6 \text { months }(n=337)\end{array}$} \\
\hline No & 252 & 74.8 \\
\hline Yes & 85 & 25.2 \\
\hline
\end{tabular}


course after graduation. A majority of the participants $(95.8 \%)$ had not attended any statistics course during last five years. Only a quarter $(25.2 \%)$ of the participants reported having looked/read a statistical report from Saudi Arabia and Qassim during past six months.

The participants' self-reported knowledge of statistics was determined on a scale of $1-10$. The median and mode of participants' self-reported knowledge was five, with a minimum of 1 and a maximum of 10 . The majority $(73.6 \%)$ of the participants self-assessed their level of statistics knowledge as five or below.

\section{Attitudes to statistics}

The Cronbach's $\alpha$ was calculated using responses to all 20 items on attitude scale. It was 0.76 , showing sufficient internal consistency. The total score for attitudes to statistics scale could be between 20 and 100. Higher scores showed a positive attitude to statistics. Most of the participants showed a high total score on the attitudes scale. The total mean score on attitudes to statistics was $71.14( \pm 7.73)$ with a minimum of 45 and a maximum of 91 . The mean total attitude score among males was $72.35( \pm 7.52)$, whereas for females it was $69.34( \pm 7.73)$. This difference was statistically significant at $P<0.001$.

Table 3 shows the mean scores of the participants on the four subscales. The participants responded to the 'perceptions of statistics and evidence-based medicine' subscale with highest scores. Having the total value between 5 and 25 , the mean score for this subscale was $21.54( \pm 2.71)$ with a minimum of 12 and a maximum of 25 . The participants responded in the negative manner to 'perceptions of knowledge and training' subscale,

Table 3 Mean subscale scores for participants' attitudes to statistics

\begin{tabular}{lll}
\hline $\begin{array}{l}\text { Serial } \\
\text { Number }\end{array}$ & Items & $\begin{array}{l}\text { Score } \\
(\text { mean } \pm \text { SD) }\end{array}$ \\
\hline 1. & $\begin{array}{l}\text { General perception } \\
\text { Perceptions of knowledge and } \\
\text { training }\end{array}$ & $16.93 \pm 3.09$ \\
3. & $\begin{array}{c}\text { Perceptions of statistics and } \\
\text { evidence-based medicine }\end{array}$ & $21.54 \pm 2.71$ \\
4. & Perceptions of future learning & $18.55 \pm 2.60$ \\
\hline
\end{tabular}

Total score for each item $=25$. as they had the lowest score on this factor. The mean score for knowledge and training perception subscale was $14.08( \pm 3.08)$ with a minimum of five and a maximum of 23 .

Table 4 displays the mean scores of the individual items. The item to which the participants responded with the highest score, was 'evidencebased medicine is important for clinical practice' $(4.53 \pm 0.70)$, followed by 'statistics is an important part of evidence-based medicine' $(4.51 \pm 0.78)$. The item to which the participants responded to with the lowest score $(2.14 \pm 0.96)$ was 'learning statistics requires a great deal of efforts' (Table 4).

Table 5 displays association of various factors with overall attitudes to statistics scores. An independent sample $t$-test was conducted to evaluate the hypothesis that males have a more positive attitude to statistics as compared with females. The test was significant, $t \quad(319)=3.464, \quad P=0.001$. Mean difference in scores among males and females was 3.01 and the $95 \%$ confidence interval for the difference in means ranged from 1.299 to 4.714.

A ANOVA was conducted to evaluate the relationship between the qualification and overall attitude scores. The independent variable, qualification, included three levels: MBBS, Diploma, and Master degree. The ANOVA was significant, $F(2,259)=3.223, P=0.041$. Post hoc tests were conducted to evaluate pairwise differences among the means. There was a significant difference in the mean scores between the MBBS and Master, $P=0.047$, but no significant difference was found between MBBS and Diploma; and Diploma and Master. Studying statistics during academic training and after graduate studies were both significantly associated with overall statistics attitude scores.

A linear regression analysis was conducted to evaluate the prediction of the total attitude scores from the age of the physician. Age was significantly related to the overall attitude scores. The correlation between age and total attitude score was 0.189 $(P<0.01)$. Accuracy in predicting the total attitude scores was mild. Approximately, $3.3 \%$ of the variance of the total attitude score was accounted for by its linear relationship with age. Linear regression analysis showed no significant prediction by the number of statistics courses attended during last five years on total attitude scores.

A multiple regression analysis was conducted to evaluate how well the general perception measures predicted total attitude scores. 
Table 4 Mean statistics attitude scores for individual items

\begin{tabular}{|c|c|c|}
\hline $\begin{array}{l}\text { Serial } \\
\text { Number }\end{array}$ & Items & $\begin{array}{l}\text { Score } \\
(\text { mean } \pm S D)\end{array}$ \\
\hline & General perception & \\
\hline 1. & I use statistics in my everyday life & $3.23 \pm 1.11$ \\
\hline 2. & Statistics should be a required part of my profession's skills & $4.21 \pm 0.79$ \\
\hline 3. & I find statistics to be very logical and clear & $3.7 \pm 1.09$ \\
\hline 4. & Statistics is a difficult subject ${ }^{a}$ & $2.78 \pm 1.09$ \\
\hline \multirow[t]{2}{*}{5.} & The medical professional would find statistics a boring subject ${ }^{a}$ & $3.03 \pm 1.14$ \\
\hline & Perceptions of knowledge and training & \\
\hline 6. & My training in statistics is adequate for my needs & $2.58 \pm 1.14$ \\
\hline 7. & When I study a research article I am able to know that the correct statistical tests are used & $3.35 \pm 1.09$ \\
\hline 8. & I normally am able to solve statistics problems without too much difficulty & $2.94 \pm 1.08$ \\
\hline 9. & I must constantly review statistics or I forget it ${ }^{a}$ & $2.38 \pm 1.00$ \\
\hline \multirow[t]{2}{*}{10.} & I am often not sure how to interpret the results of statistical tests ${ }^{a}$ & $2.82 \pm 1.01$ \\
\hline & Perceptions of statistics and evidence-based medicine & \\
\hline 11. & Evidence-based medicine is important for clinical practice & $4.53 \pm 0.70$ \\
\hline 12. & Statistics is a necessary skill for a clinician interested in practicing evidence-based medicine & $4.43 \pm 0.74$ \\
\hline 13. & Statistics is an important part of evidence-based medicine & $4.51 \pm 0.78$ \\
\hline 14. & Knowledge of statistics is necessary when evaluating medical literature & $4.33 \pm 0.76$ \\
\hline \multirow[t]{2}{*}{15.} & Statistics is only useful to someone who conducts research ${ }^{a}$ & $3.75 \pm 1.17$ \\
\hline & Perceptions of future learning & \\
\hline 16. & I can learn statistics & $4.13 \pm 0.80$ \\
\hline 17. & I would like to study statistics & $4.20 \pm 0.89$ \\
\hline 18. & Learning statistics requires a great deal of efforts ${ }^{a}$ & $2.14 \pm 0.96$ \\
\hline 19. & The thought of taking a statistics course gives me an unpleasant feeling ${ }^{a}$ & $3.68 \pm 1.16$ \\
\hline 20. & Given the opportunity, I would take a statistics course & $4.39 \pm 0.77$ \\
\hline
\end{tabular}

${ }^{a}$ The negative statements were recoded; higher scores mean positive attitudes.

Table 5 Association of various factors with overall statistics attitude scores

\begin{tabular}{|c|c|c|}
\hline Variables & $\begin{array}{l}\text { Score } \\
(\text { mean } \pm \text { SD) }\end{array}$ & Significance level \\
\hline $\begin{array}{l}\text { Gender } \\
\text { Male } \\
\text { Female }\end{array}$ & $\begin{array}{l}72.35( \pm 7.52) \\
69.34( \pm 7.73)\end{array}$ & $t(319)=3.464, P=0.001$ \\
\hline $\begin{array}{l}\text { Qualificatior } \\
\text { MBBS } \\
\text { Diploma } \\
\text { Master }\end{array}$ & $\begin{array}{l}71.03 \pm 7.99 \\
72.71 \pm 5.80 \\
76.68 \pm 3.94\end{array}$ & $F(2,259)=3.223, P=0.041$ \\
\hline $\begin{array}{l}\text { Studied stat } \\
\text { Yes } \\
\text { No }\end{array}$ & $\begin{array}{c}\text { ics during aca } \\
72.10 \pm 7.20 \\
69.59 \pm 8.21\end{array}$ & $\begin{array}{l}\text { lemic training } \\
t(320)=2.899, P=0.004\end{array}$ \\
\hline $\begin{array}{l}\text { Attended sta } \\
\text { Yes } \\
\text { No }\end{array}$ & $\begin{array}{r}\text { stics course/s } \\
73.44 \pm 8.55 \\
70.69 \pm 7.51\end{array}$ & $\begin{array}{l}\text { fter graduation } \\
t(318)=2.253, P=0.025\end{array}$ \\
\hline
\end{tabular}

The predictors were five items in the general perception subscale, whereas the dependent variable was total attitude scores. The linear combination of general perception measures was significantly related to the total attitude scores, $F(5,272)=136.736, P<0.0001$. The adjusted $r^{2}$ indicated $\sim 71 \%$ of the variance of total attitude scores in the sample can be accounted for by the general perception items.

The participants were asked if they had used the data in their health centers for any academic or educational purpose. Out of 338 total responses, $190(56.2 \%)$ reported having used data for educational purposes. Mostly the data for hypertension, diabetes mellitus, and immunization were used for this purpose.

The vast majority of the participants responded affirmatively to the need for learning statistics. On enquiring about their perceived need to learn statistics, 314 (92.9\%) participants showed their desire to learn statistics. Responding to the suggested topics, $237(70.1 \%)$ participants provided a total of 318 suggestions. Out of the total suggestions, $26.7 \%$ were related to epidemiology topics such as study designs and topics concerning 
evidence-based medicine. The rest of the suggestions included general statistics covering all topics of statistics; specific topics of descriptive statistics and inferential statistics. Topics unrelated to statistics, such as clinical features and management of chronic diseases, were proposed in $23.3 \%$ suggestions.

\section{Discussion}

The results of our study suggest that PHC physicians are aware of the importance of statistics in their professional career, and also realize their lack of competence in statistics. Other studies have also reported similar findings among physicians (West and Ficalora, 2007). Our survey had a high response rate and good completeness of the questions, which may indicate the interest of study participants in statistics. A substantial proportion of our study participants $(59.6 \%)$ had studied statistics during their academic training, which can be explained by the fact that nowadays statistics is a core module of many medical schools' curricula (Dommisse and Joubert, 2009). This finding is in contrast to another study in which a survey of 62 physicians in surgical residency programs found that only $33 \%$ had formal statistics teaching in their medical schools (Cheatham, 2000). This difference may be explained by the fact that the study by Cheatham (2000) included the respondents graduating before the year 2000. Anecdotal evidence suggests that since then the curricula for most of the medical institutions have been reviewed with the inclusion of statistics or equivalent courses.

In our study, only $15.2 \%$ participants had attended a statistics course after graduation, and the vast majority (95.8\%) had not attended a statistics course during last five years. This finding may reflect the lack of availability of statistics training courses at PHC level. It underscores the importance of conducting training courses for PHC physicians to familiarize them with basic statistics. In spite of substantial number of relevant documents available online as well as in the form of hard copies, only a small proportion $(25 \%)$ of participants had read/looked at reports about health statistics in Qassim or Saudi Arabia. This finding may reflect a lack of awareness of the PHC physicians about the availability of these reports.
Moreover, they are heavily committed to their clinical duties, and are not obligated to conduct research or prepare scientific reports related to their work. Thus, the work environment is not very supportive in encouraging the physicians to engage in research, scientific, or academic activities. Lack of interest in statistical reports can also be explained by the self-reported low level of knowledge of statistics in our study, with almost three-quarter of the participants self-assessing themselves as below average. This finding is reported in other studies in which physicians have self-reported lack of competence in statistics (West and Ficalora, 2007). Ercan et al. (2008) also found an insufficient knowledge of statistics among physicians.

The results of this study indicate that the participating PHC physicians had a positive attitude to statistics. Several studies conducted with the health care workers, including physicians (West and Ficalora, 2007), medical students (Hannigan et al., 2014; Stanisavljevic et al., 2014), and nurses (Baghi and Kornides, 2013), have shown a positive attitude to statistics, and the participants appreciated the importance of statistics in their professional career.

In our study, significant associations were found between total attitude scores and age, qualification, and studying statistics during academic training and after graduation. Other studies have also found that the realization of the importance of statistics increases with increase in age, qualification, and status. Ercan et al. (2008) found that the senior staff, involved in academic activities, believed more in the importance of statistics in professional carrier as compared with residents and students, in a medical school in Turkey. However, other studies from Malaysia (Daher and Amin, 2010), Pakistan (Ahmad et al., 2009), and Croatia (Hren et al., 2004) have shown positive attitude of medical students to statistics and its significance in medical curriculum.

In our study, males scored higher on attitude scale showing a more positive attitude in comparison to females. Although the difference between mean scores was small, it was statistically significant. Another study conducted among medical students found that on attitude scales, the males scored higher as compared with females; however, the difference was not statistically significant (Hannigan et al., 2014). 
The analysis of the four subscales of attitudes to statistics scale showed interesting findings. The results of "perceptions of statistics and evidencebased medicine' subscale analysis, showed highest scores, followed by 'perceptions of future learning'. 'Perceptions of knowledge and training' was the least scoring subscale.

Overall, the participants had a positive general perception toward statistics. Among the general perception items, 'Statistics should be a required part of my profession's skills' scored the highest $(4.21 \pm 0.79)$ reflecting realization of importance of statistics in their professional life and a desire to have knowledge and skills of statistics.

'Evidence-based medicine is important for clinical practice', was the highest scoring $(4.53 \pm 0.70)$ item of the subscale 'perceptions of statistics and evidence-based medicine'. Supporting the finding of our study, previous studies have also shown the awareness of health care professionals regarding the importance of statistics in evidence-based medicine. A survey of practicing clinicians found that knowledge of statistics is considered useful in many aspects of clinical practice including comprehension of clinical guidelines and evidence summaries, explaining levels of risk to patients, and interpreting the results of a screening test (Swift et al., 2009). Moreover, health care professionals require the knowledge of statistics for medical practice and understanding of medical issues (Freeman et al., 2008). The published medical literature cannot be critically evaluated without basic knowledge of statistics (Daher and Amin, 2010; Stanisavljevic et al., 2014). It is also reported that the health care professionals who feel competent to understand research are more likely to practice evidence-based medicine (Baghi and Kornides, 2013).

The scores on 'perceptions of future learning' subscale were the second highest. It shows that the physicians not only realize the importance of statistics and evidence-based medicine but are also keen to learn the subject of statistics. This is in accordance with the studies conducted with professionals in health care organizations where statistics and evidence-based medicine were considered important for their practice, and the need of proper understanding of statistics was clearly recognized by physicians (West and Ficalora, 2007). The physicians believed that their routine work as a doctor required knowledge of epidemiology, statistics, and analysis skills (Miles et al., 2010).

The participants scored the lowest in the 'perceptions of knowledge and training' subscale, indicating that they realize the inadequacy of their knowledge and training in statistics. Even physicians with statistical training and substantial research experience have been found to think that they lack required competence in statistics (West and Ficalora, 2007). Studies have also demonstrated that practicing physicians had poor understanding of common statistical tests and their ability to interpret study results was limited (Windish et al., 2007). Factors related to the lack of knowledge and training include the perception of statistics as a difficult field, lack of sufficiently understanding the importance of statistics, inadequate statistics training in the medical schools, and lack of utilization of problembased approach during statistics teaching (Bland, 2004; Kilic and Celik, 2013). Moreover, a survey found that many physicians had not recognized the value of their undergraduate teaching in statistics, but had subsequently found the skills relevant to their career (Miles et al., 2010).

In our study, the vast majority of participants (92.9\%) expressed their perceived need to learn statistics. They suggested a number of topics for the training courses, which indicates their interest in statistics. However, many suggestions related to the topics of evidence-based medicine shows the clinical context of the PHC physicians.

Our study surveyed PHC physicians at a single province. Differences in qualification and work environment of participants, may limit generalizations to other settings. However, the participants in our study represented a diverse population of physicians from various Middle Eastern, South Asian, and African countries. Other provinces of the country have a similar composition of PHC physicians, making it possible to generalize our findings to other provinces. A self-administered questionnaire may also limit the validity of findings. Being a selfreporting survey, recall bias and misunderstanding of the questions may have occurred, contributing to inaccuracies in the data. However, efforts had been made to clear any ambiguity by making amendments after pretest. Non-response bias is minimal in this survey as the response rate was high, and mostly the non-responders were those who were on vacations, at the time of the survey. 


\section{Conclusion}

Our study results suggest that the PHC physicians have a positive attitude to statistics. They realize their gaps in knowledge in statistics and are keen to improve their knowledge. However, surveys for determining attitudes need to be done periodically because of high turnover and diversity of the health care workforce in Saudi Arabia. Moreover, change in statistical skills and attitudes to statistics may occur because of changing curricula with a focus on biostatistics and research in medical schools.

\section{Implications for policy and practice}

To promote the use of statistics in PHC in Qassim, strategies must be adopted to involve PHC physicians in handling data, and to improve their statistics knowledge and skills. PHC physicians may be involved in managing data by making them realize that the available data are valuable in assessing their work. Regular statistics training programs and supportive work environment may be helpful in improving knowledge and skills of the physicians. A regular statistics course could be added in the annual Academic Calendar of Public Health Administration, developed according to the needs of PHC physicians. The statistics training should cover basic statistics and focus on the role of statistics in clinical decision making, and ability to interpret medical research. Building statistical skills using courses is expected to improve the skills especially related to the critical appraisal of the published literature. With an improved knowledge of statistics, better clinical care utilizing evidence-based medicine is expected, leading to an improvement in health care services.

\section{Acknowledgments}

The authors are grateful to all survey respondents for their valuable time and efforts in completing the survey. The authors also wish to thank all District Supervisors and Primary Health Care Centre Directors of Qassim province who actively participated in data collection. The authors are thankful to Ms Resa Bedeo, Office Secretary at Research and Information Unit, for her valuable secretarial tasks.

\section{Financial Support}

This research received no specific grant from any funding agency, commercial, or not-for-profit sectors.

\section{Conflicts of Interest}

None.

\section{Ethical Standards}

The study was approved by Regional Research Ethics Committee, Qassim, Saudi Arabia.

\section{References}

Ahmad, F., Zehra, N., Omair, A. and Anjum, Q. 2009: Students' opinion regarding application of Epidemiology, Biostatistics and Survey Methodology courses in medical research. The Journal of the Pakistan Medical Association 59, 307-10.

Ajzen, I. 1991: The theory of planned behavior. Organizational Behavior and Human Decision Process 50, 179-211.

Baghi, H. and Kornides, M.L. 2013: Current and future health care professionals attitudes toward and knowledge of statistics: how confidence influences learning. Journal of Nursing Education and Practice 3, 24-9.

Bland, J.M. 2004: Teaching statistics to medical students using problem-based learning: the Australian experience. $B M C$ Medical Education 4, 31; doi:10.1186/1472-6920-4-31.

Cheatham, M.L. 2000: A structured curriculum for improved resident education in statistics. The American Surgeon 66, 585-88.

Daher, A.M. and Amin, F. 2010: Assessing the perceptions of a biostatistics and epidemiology module: views of year 2 medical students from a Malaysian university. A crosssectional survey. BMC Medical Education 10, 34; doi:10.1186/1472-6920-10-34.

DeBarr, K.A. 2004: A review of current health education theories. Californian Journal of Health Promotion 2 (1), 74-87.

Dommisse, J. and Joubert, G. 2009: Profile of research methodology and statistics training of undergraduate medical students at South African universities. South African Family Practice 51, 158-61. Retrieved 30 June 2015 from http://www. ajol.info/index.php/safp/article/view/43671

Ercan, I., Ozkaya, G., Ocakoglu, G., Yazici, B., Sezer, A., Ediz, B. and Kan, I. 2008: Determining biostatistics knowledge of students and physicians in medical school. Retrieved 30 June 2015 from http://interstat.statjournals.net/YEAR/ 2008/articles/0801003.pdf

Freeman, J.V., Collier, S., Staniforth, D. and Smith, K.J. 2008: Innovations in curriculum design: a multi-disciplinary approach to teaching statistics to undergraduate medical students. BMC Medical Education 8, 28; doi:10.1186/14726920-8-28. 
Green, S.B. and Salkind, N.J. 2011. Using SPSS for Windows and Macintosh: analyzing and understanding data, sixth edition. Upper Saddle River, NJ: Pearson.

Hannigan, A., Hegarty, A.C. and McGrath, D. 2014: Attitudes towards statistics of graduate entry medical students: the role of prior learning experiences. BMC Medical Education 14, 70; doi:10.1186/1472-6920-14-70.

Ministry of Health. 2013. Health Statistical Year Book 1434H. Kingdom of Saudi Arabia: Ministry of Health, Retrieved 30 June 2015 from http://www.moh.gov.sa/en/ Ministry/Statistics/book/Documents/Statistics-Book-1434. pdf

Hren, D., Lukić, I.K., Marusić, A., Vodopivec, I., Vujaklija, A., Hrabak, M. and Marusić, M. 2004: Teaching research methodology in medical schools: students' attitudes towards and knowledge about science. Medical Education 38, 81-86.

Kilic, I. and Celik, B. 2013: The views of academic staff on biostatistics education in health sciences. International Journal of Health Sciences (Qassim) 7, 142-49.

Mathew, L. and Aktan, N.M. 2014: Nursing student attitudes toward statistics. Journal of Nursing Education 53, 233-37.

Miles, S., Price, G.M., Swift, L., Shepstone, L. and Leinster, S.J. 2010: Statistics teaching in medical school: opinions of practising doctors. BMC Medical Education 10, 75; doi:10.1186/1472-6920-10-75

Rashid, A. and Subramaniam, G. 2012: Use of biostatistics among practicing doctors in Penang, Malaysia. The Internet
Journal of Medical Education 2, 1-8. Retrieved 30 June 2015 from http://ispub.com/IJME/2/2/14280

Sami, W. 2010: Biostatistics education for undergraduate medical students. Biomedica 6, 80-84 Retrieved 30 June 2015 from http://www.thebiomedicapk.com/articles/207.pdf

Schiavo, R. 2007. Health communication: from theory to practice. San Francisco, CA: Jossey-Bass.

Stanisavljevic, D., Trajkovic, G., Marinkovic, J., Bukumiric, Z., Cirkovic, A. and Milic, N. 2014: Assessing attitudes towards statistics among medical students: psychometric properties of the Serbian version of the Survey of Attitudes Towards Statistics (SATS). PLoS ONE 9, e112567; doi:10.1371/ journal.pone.0112567.

Swift, L., Miles, S., Price, G.M., Shepstone, L. and Leinster, S.J. 2009: Do doctors need statistics? Doctors' use of and attitudes to probability and statistics. Statistics in Medicine 28, 1969-981.

West, C.P. and Ficalora, R.D. 2007: Clinician attitudes toward biostatistics. Mayo Clinic Proceedings 82, 939-43.

Windish, D.M., Huot, S.J. and Green, M.L. 2007: Medicine residents' understanding of the biostatistics and results in the medical literature. JAMA 298, 1010-22.

Zhang, Y., Shang, L., Wang, R., Zhao, Q., Li, C., Xu, Y. and Su, H. 2012: Attitudes toward statistics in medical postgraduates: measuring, evaluating and monitoring. BMC Medical Education 12, 117; doi:10.1186/1472-6920-12-117.

Zimprich, D. 2012: Attitudes toward statistics among Swiss psychology students. Swiss Journal of Psychology 71, 149-55. 